\author{
Mateusz SZUBEL ${ }^{1}$ \\ Mariusz FILIPOWICZ ${ }^{2}$
}

\title{
ANALIZA NUMERYCZNA PRACY URZĄDZEŃ GRZEWCZYCH MAŁEJ MOCY ZASILANYCH BIOMASA
}

\begin{abstract}
Współczesne urządzenie grzewcze niewielkiej mocy, do zastosowań w energetyce rozproszonej, powinno cechować się wysoką sprawnością konwersji energii i parametrami pracy spełniającymi wymagania, związane $\mathrm{z}$ ochroną środowiska. Ponadto istotne jest zachowanie prostoty budowy, co pozwala na redukcję kosztów wykonania takiej jednostki. Analiza numeryczna to obecnie najefektywniejsza forma prowadzenia procesu optymalizacji parametrów pracy pieców, czy kotłów, ze względu na szybkość uzyskiwania wyników i brak konieczności wykonania kolejnych prototypów. Sprowadzenie rzeczywistego urządzenia do postaci modelu teoretycznego pozwala na rozwiązanie wielu problemów, dotyczących m.in. optymalizacji transferu ciepła, dystrybucji powietrza w procesie spalania, charakterystyki procesu spalania, czy parametrów spalin. W artykule przedstawiono szereg możliwości zastosowania narzędzi analizy numerycznej do określenia parametrów pracy wymiennika akumulacyjnego, stanowiącego element instalacji pieca grzewczego małej mocy, zasilanego biomasą (głównie drewnem kawałkowym). W ramach prac badawczych wykonano pomiary temperatury spalin i prędkości ich przepływu wewnątrz kanału wymiennika. Walidację modelu przeprowadzono na podstawie pomiaru temperatury na wlocie $\mathrm{i}$ wylocie $\mathrm{z}$ przewodu, łączącego komorę spalania z czopuchem, przy czym osiągnięty został satysfakcjonujący stopień zgodności danych eksperymentalnych i rezultatów obliczeń. Prezentowane wyniki symulacji pozwoliły m.in. na ocenę wpływu geometrii akumulacyjnego wymiennika ciepła na stopień odzysku energii cieplnej ze spalin oraz obserwację rozkładu temperatury na powierzchni masy akumulacyjnej. Przeprowadzono także analizy, dotyczące charakterystyki przepływu gazów w obrębie kanału spalinowego wymiennika.
\end{abstract}

Słowa kluczowe: piece na biomasę, modelowanie numeryczne, CFD, drewno

\footnotetext{
${ }^{1}$ Autor do korespondencji: Mateusz Szubel, AGH Akademia Górniczo - Hutnicza, Wydział Energetyki i Paliw, Katedra Zrównoważonego Rozwoju Energetycznego, Al. A. Mickiewicza 30, 30-059 Kraków, 0126173428, mszubel@agh.edu.pl.

2 Mariusz Filipowicz, AGH Akademia Górniczo - Hutnicza, Wydział Energetyki i Paliw, Al. A. Mickiewicza 30, 30-059 Kraków, 0126175192, filipow@agh.edu.pl.
} 


\section{Wstęp}

\subsection{Urządzenia grzewcze zasilane biomasą a generacja rozproszona}

Aż do epoki industrialnej, drewno stanowiło podstawowy nośnik energii pierwotnej [1]. Obecnie ze względu na ogromną popularność biopaliw i potencjał energetyczny biomasy, wykorzystanie drewna jako paliwa wzrasta. Niska zawartość popiołu (rzędu 1\% dla drewna odpadowego [2]), siarki czy chloru (po ok. 0,1\% dla drewna odpadowego [2]), a także dostępność i koszt paliwa zdecydowanie niższy w porównaniu z węglem i gazem ziemnym, to argumenty, które sprawiają, iż rzesza zwolenników ogrzewania domów ciepłem z drewna rośnie. Doświadczenia wskazują, iż ze względów technologicznych i logistycznych wykorzystanie biomasy w instalacjach polskiej energetyki zawodowej, opartej na węglu jest niezwykle problematyczne. Mimo to, w najbliższej przyszłości warto wciąż rozpatrywać biomasę jako nośnik energii pierwotnej, w tym szczególnie słomę i drewno, w kontekście dążeń do wypełnienia zobowiązań międzynarodowych, dotyczących zwiększania udziału energii ze źródeł odnawialnych (OZE) w całkowitym zużyciu energii końcowej. Szczególnie zasadne zdaje się stosowanie drewna w domowych urządzeniach grzewczych, przystosowanych lub dedykowanych do spalania tego typu paliwa. w odpowiedzi na wzrastającą popularność kotłów zasilanych drewnem, w ostatnich latach producenci zaoferowali wiele nowych jednostek z serii tzw. „kotłów zgazowujących” (przykładem mogą być urządzenia opisane w [3, 4]), zasilanych drewnem kawałkowym (szczapy), o mocach od kilkunastu nawet do 100kW. Inny kierunek rozwoju generacji rozproszonej opartej na drewnie to piece ze zintegrowanym ceramicznym wymiennikiem akumulacyjnym. Są to wysokosprawne jednostki grzewcze, cechujące się zdecydowanie prostszą niż kotły zgazowujące budową i zasadą działania. Komora paleniskowa nowoczesnej jednostki tego typu konstrukcyjnie zbliżona jest do klasycznych wkładów kominkowych $\mathrm{z}$ szybą, przy czym korpus paleniska wykonany jest $\mathrm{z}$ materiału ceramicznego [5].

\subsection{Akumulacyjne wymienniki ciepła}

W przypadku pieców na drewno ze zintegrowanym wymiennikiem akumulacyjnym, właśnie ten ostatni element decyduje o wysokim stopniu wykorzystania energii zawartej w paliwie.

Dzięki zastosowaniu przewodu dymowego w postaci ceramicznego (akumulacyjnego) kanału, wymuszającego wielokrotne zmiany kierunku ruchu spalin, droga ich przepływu do zasadniczej części komina zostaje wydłużona. Skutkuje to ogrzaniem materiału akumulacyjnego kosztem temperatury spalin. Materiał, z którego wykonany jest taki wymiennik ciepła powinien być dobrany tak, aby pojemność cieplna i współczynnik przewodzenia ciepła $(\lambda)$ były możliwie jak najwyższe, dzięki czemu energia cieplna przejęta w przewodzie dy- 
mowym jest oddawana długo i równomiernie (nawet przez 8 do 12 godzin [5]). Akumulacyjne wymienniki ciepła budowane są z prefabrykowanych elementów odlewanych w formach. Przykład podstawowego modułu do budowy masy akumulacyjnej pieca na drewno przedstawiony jest na rysunku 1.

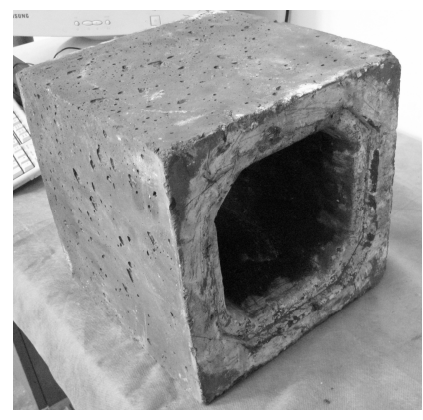

Rys. 1. Przykład podstawowego ceramicznego elementu prefabrykowanego do budowy akumulacyjnego wymiennika ciepła

Fig. 1. An example of basic prefabricated ceramic element of accumulative heat exchanger

\subsection{Analiza pracy i proces optymalizacji urządzeń grzewczych małej mocy $z$ wykorzystaniem metod numerycznych}

Proces implementacji przepisów wprowadzanych przez Unię Europejską (UE) wymusza zwiększanie sprawności urządzeń grzewczych oraz redukcję emisji zanieczyszczeń do poziomu niższego niż obowiązujące progi (np. w przypadku pieców z paleniskiem i wymiennikiem akumulacyjnym wymagania określa [6]).

Osiąganie satysfakcjonujących warunków pracy urządzeń grzewczych wymaga ciągłej optymalizacji ich parametrów. Efektywną metodę wspomagania decyzji w zakresie wdrażania innowacji technicznych stanowi modelowanie numeryczne, w tym CFD (ang. „Computational Fluid Dynamics”) - narzędzie łączące eksperymentalne i analityczne podejście do badań naukowych, poprzez umożliwianie wykonywania symulacji, związanych przede wszystkim z przepływem płynów i transferem ciepła w obrębie jednego i wielu ośrodków [7].

\section{Charakterystyka badanego wymiennika akumulacyjnego oraz celu analizy numerycznej}

W dalszej części niniejszego artykuł opisano proces przygotowania oraz rezultaty symulacji numerycznej pracy akumulacyjnego wymiennika ciepła, zintegrowanego z piecem dedykowanym do spalania drewna. Analizy eksperymentalne przeprowadzono w oparciu o jednostkę widoczną na rysunku 2. 
W przypadku badanego urządzenia, spaliny opuszczające komorę spalania przemieszczają się w górę, ponad deflektor, a następnie do kanału wymiennika, stanowiącego ,ścianę grzewczą" umieszczoną obok paleniska.

Wymiennik zbudowany jest $\mathrm{z}$ betonu akumulacyjnego. Kanał wewnętrzny tworzy „,meander”, przy czym zmiana kierunku następuje w każdym kolejnym rzędzie prefabrykowanych elementów. Szyber zamontowany w centralnym elemencie nad komorą paleniskową umożliwia skierowanie strumienia gorących spalin do wymiennika, a następnie pionowym odcinkiem kanału do najniższego jego poziomu, albo bezpośrednio do komina. Ta ostatnia nastawa jest stosowana w fazie rozpalania wsadu paliwa, dla uzyskania odpowiedniego podciśnienia - ciągu kominowego.

a)

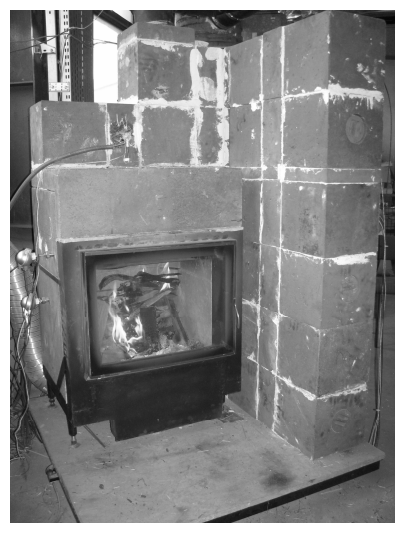

b)

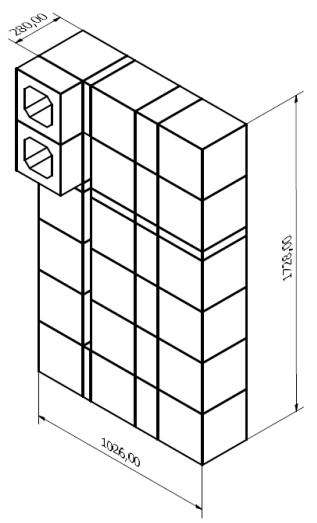

Rys. 2. Piec na biomasę złożony z paleniska oraz akumulacyjnego wymiennika ciepła: (a) kompletna jednostka, (b) schemat wymiennika

Fig. 2. Biomass furnace consist of the fireplace and the accumulative heat exchanger: (a) complete unit, (b) schematic of exchanger

Celem analizy numerycznej opisanego wyżej wymiennika było zbadanie wpływu geometrii kanału wewnętrznego na prędkość i turbulentność strumienia spalin oraz obserwacja stopnia nagrzewania się róznych obszarów konstrukcji. Rozkład temperatury obserwowano dla powierzchni zewnętrznej wymiennika oraz dla przekroju poprzecznego, gdzie możliwa była jednoczesna analiza wartości temperatury w róznych obszarach masy akumulacyjnej i strumienia spalin.

Informacje zdobyte $\mathrm{w}$ wyniku obliczeń mogą stanowić podstawę zmian w zakresie budowy całego wymiennika oraz indywidualnych elementów konstrukcyjnych, dostarczają danych dotyczących optymalnych wymiarów (szczególnie wysokości) wymiennika, punktów usytuowania 
wyczystek, czy czujników pomiarowych zintegrowanych z ewentualnym kontrolerem procesu spalania.

\section{Model numeryczny akumulacyjnego wymiennika ciepła}

Do przeprowadzenia obliczeń wykorzystano komercyjne oprogramowanie ANSYS CFX, wchodzace w skład środowiska ANSYS Workbench 14.

Ze względu na charakter modelowanych zjawisk, zachodzących w obrębie rozpatrywanego wymiennika ciepła, na potrzeby przeprowadzenia symulacji zdefiniowano dwie domeny, reprezentujące materiał akumulacyjny (ciało stałe) oraz strumień spalin wewnątrz kanału (płyn). Następnie domeny zostały poddane indywidualnej obróbce w zakresie generacji siatki, definicji warunków brzegowych, wartości parametrów fizycznych itp. Sprzężenie obydwu części modeli zrealizowano za pośrednictwem funkcji „Interface”. Rysunek 3 prezentuje budowę modelu w środowisku Workbench 14.

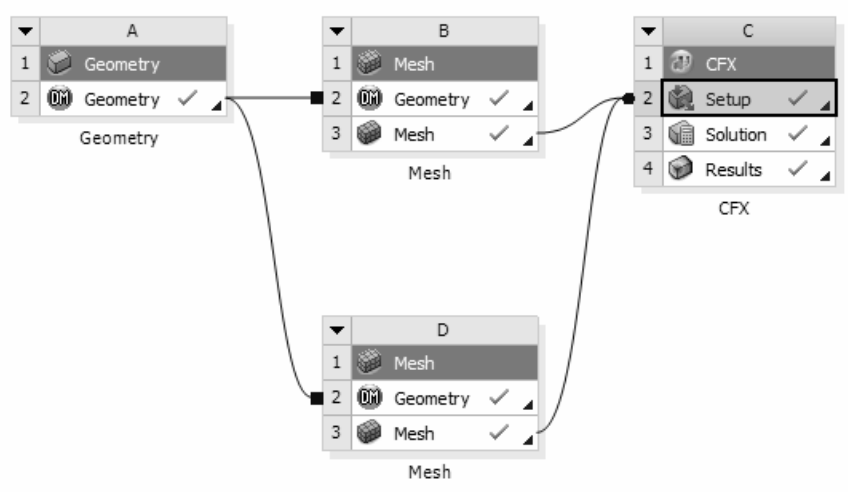

Rys. 3. Zależności pomiędzy poszczególnymi elementami modelu reprezentującymi procesy przygotowania i przeprowadzenia symulacji

Fig. 3. Relations between elements of model, which represent processes of preparation and performance of the simulation

\subsection{Geometria i siatka}

Projekt wymiennika ciepła został wykonany w programie Inventor2013, a następnie zaimportowany do środowiska ANSYS Workbench 14, gdzie za pośrednictwem narzędzia „Design Modeler” geometria została przeniesiona do generatora siatek „ANSYS Meshing”. Zarówno w przypadku domeny płynu, jak i ciała stałego, siatka została wygenerowana automatycznie, przy czym w pierwszym przypadku liczba elementów siatki wyniosła $7 \cdot 10^{4}$, w drugim natomiast $7,7 \cdot 10^{4}$. Dalsze zagęszczanie siatki okazało się bezzasadne, z uwagi na uzyskanie zadowalającej zbieżności wyników obliczeń i danych 
z pomiarów eksperymentalnych. Widok ogólny wygenerowanych siatek jest prezentowany na rysunkach 4-a, 4-b. Dodatkowo rysunek 4-c przedstawia przekrój poprzeczny wymiennika.

a)

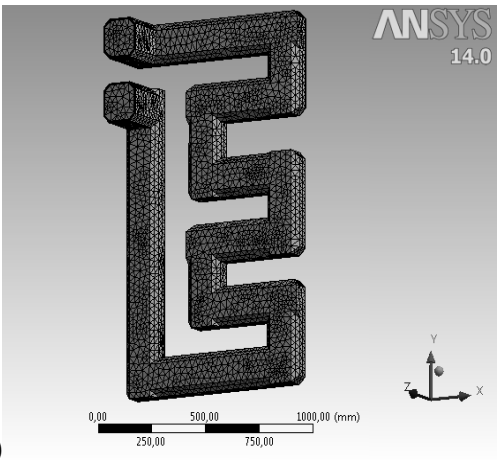

c)

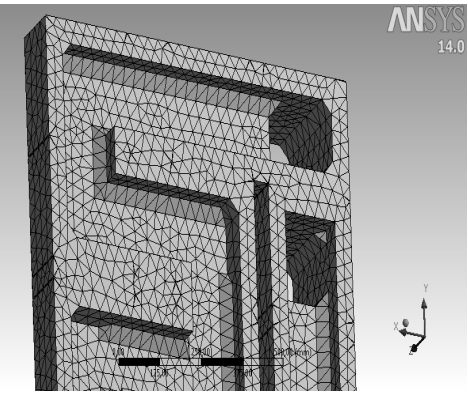

b)

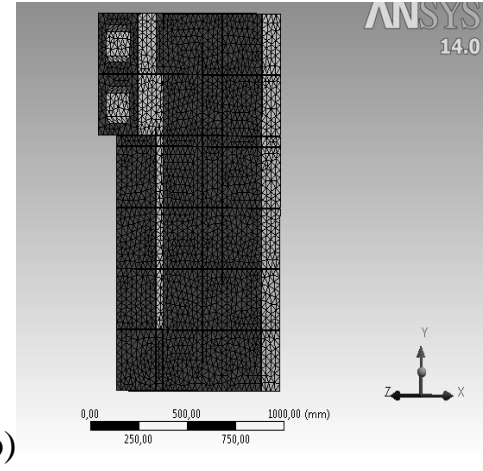

d)

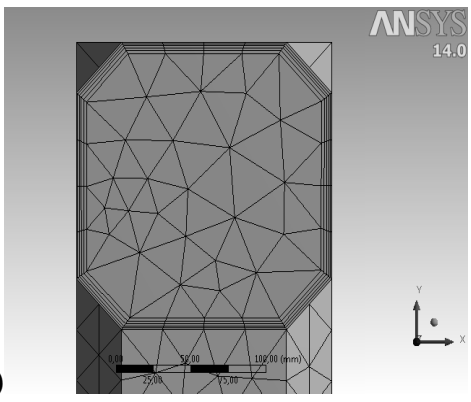

Rys. 4. Siatki wygenerowane dla domeny płynu i wymiennika: (a) płyn - widok ogólny, (b) wymiennik - widok ogólny, (c) warstwa przyścienna płynu, (d) przekrój przez wymiennik

Fig. 4. Meshes generated for fluid and solid domain: (a) fluid - general view, (b) solid - general view, (c) cross-section of heat exchanger, (d) inflation layer in fluid domain

W celu uchwycenia zjawisk zachodzących w warstwie przyściennej płynu, siatka została w tym obszarze zagęszczona. Zastosowano 5 warstw, przy współczynniku wzrostu grubości warstwy równym 1,2 i maksymalnej grubości warstwy równej $5 \mathrm{~mm}$. Siatka w obszarze warstwy przyściennej jest widoczna na rysunku 4-d.

\subsection{Dobór warunków brzegowych oraz parametrów obliczeń}

Uwzględnienie zjawisk turbulencji przepływu spalin zrealizowano poprzez zastosowanie modelu turbulencji SST (ang. Shear - Stress Transport), rekomendowanego dla tego typu obliczeń [7]. Jest to podejście bazujące na połączeniu równań modelu k- $\varepsilon$ oraz k- $\omega$, przy czym o wykorzystaniu danego modelu decyduje wartość funkcji dwustanowej (0 lub $1 \mathrm{w}$ zależności od położenia obli- 
czanego elementu względem ścianki domeny). W zakresie warunków inicjalizacji przepływu spalin założono dla tej domeny średnią intensywność turbulencji na poziomie 5\%. Przyjęto, iż jest to domena ciągła. Pominięto natomiast oddziaływania wynikające $\mathrm{z}$ siły grawitacji. Dane graficzne prezentowane w dalszej części artykułu wygenerowano w post - procesorze dla prędkości płynu na wlocie do wymiennika równej $0,2 \mathrm{~m}^{-1} \mathrm{~s}^{-1}$ i temperatury $300^{\circ} \mathrm{C}$. Parametrem zdefiniowanym na wylocie $\mathrm{z}$ wymiennika było podciśnienie równe -12Pa (jest to wartość zalecana przez producenta dla analizowanego urządzenia). Płaszczyznę przekroju wymiennika, przebiegającą prostopadle do podłoża w równej odległości od obu dużych powierzchni grzewczych wymiennika akumulacyjnego zdefiniowano jako płaszczyznę symetrii. Założono temperaturę pokojową $\left(20^{\circ} \mathrm{C}\right) \mathrm{w}$ otoczeniu jednostki grzewczej.

Pomiar temperatury wejściowej spalin wykonywano przy użyciu termopary PTTK, natomiast temperaturę wyjściową mierzono czujnikiem rezystancyjnym PT100. W celu określenia prędkości płynu wykonano szereg pomiarów sondą anemometryczną (DELTA OHM), przy czym sonda była umieszczana w otworach wywierconych w wybranych punktach akumulacyjnego wymiennika ciepła. Odpowiednią wartość ciągu kominowego zapewniała nastawa miarkownika ciągu, zamontowanego na przewodzie dymowym.

\section{Prezentacja i omówienie wyników symulacji pracy akumula- cyjnego wymiennika ciepła}

Rysunek 5-a prezentuje rozkład temperatury na powierzchni akumulacyjnego wymiennika ciepła przy ustabilizowanym strumieniu energii przez ściankę konstrukcji do otoczenia. $\mathrm{Z}$ uwagi na fakt stopniowego wychładzania się spalin obserwujemy systematyczny spadek temperatury powierzchni zewnętrznej kanału w miarę przemieszczania się ku wylotowi. Porównanie rysunku 5-a z rysunkiem 5-b umożliwia zaobserwowanie wpływu wielokrotnych zmian kierunku przepływu spalin na rozkład temperatury w obrębie wymiennika. Obszary, w których obserwujemy dużą turbulentność przepływu oraz relatywnie niską prędkość strumienia spalin cechują się intensywniejszym transferem ciepła z płynu do ścianek wymiennika. W związku z tym także temperatura notowana na powierzchni ściany zewnętrznej jest wyższa. Wewnętrzne „półki” tworzone przez meander kanału są wyraźnie chłodniejsze niż ściany zewnętrzne wymiennika, ze względu na nagły wzrost prędkości strumienia spalin, przepływającego pod półką do obszaru wzniesienia się na kolejną kondygnację wymiennika i zmiany kierunku ruchu. 


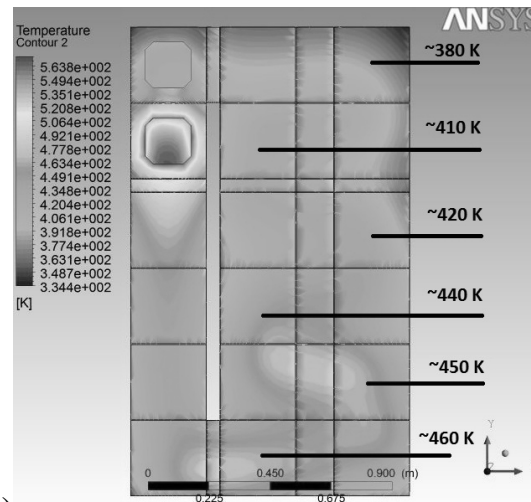

Rys. 5. Przykładowe rezultaty symulacji numerycznej pracy akumulacyjnego wymiennika ciepła: (a) rozkład temperatury na powierzchni ściany, (b) linie prezentujące przepływ płynu

Fig. 5. Examples of results of numerical simulation of accumulative heat exchanger operation: (a) distribution of temperature on the surface of wall, (b) stream lines of fluid flow

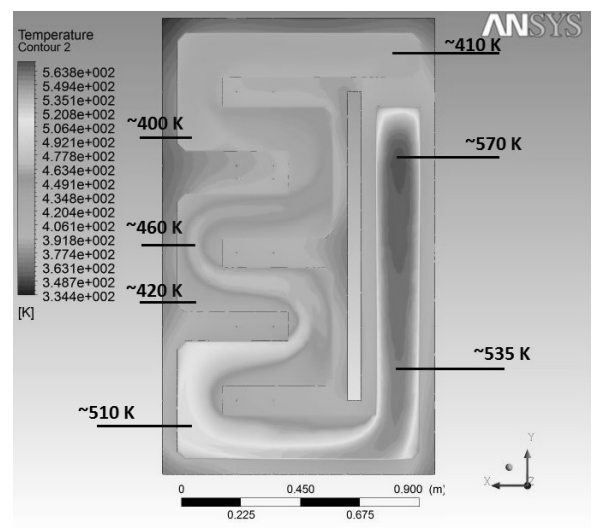

Rys. 6. Rozkład temperatury w obrębie wymiennika ciepła i płynu dla przekroju poprzecznego (płaszczyzna symetrii)

Fig. 6. Distribution of temperature in area of heat exchanger and fluid in cross-section (symmetry plane)

$\mathrm{Na}$ podstawie rysunku 6 można stwierdzić, iż moc paleniska w rozpatrywanym układzie pozwala na niewielkie zwiększenie wymiarów wymiennika, z uwagi na relatywnie wysoką temperaturę spalin ulatujących do komina.

Na poniższym wykresie (Rys. 7.) widoczne jest porównanie krzywej temperatury na wylocie $\mathrm{z}$ wymiennika spalin, mierzonej przez termoparę i wybranych punktów, stanowiących wynik symulacji. W wyniku symulacji uzyskano satysfakcjonujący poziom zbieżności obliczeń z danymi pomiarowy- 
mi, przy czym najwyższa wartość odchyłki bezwzględnego dla danego punktu wyniosła $6,5 \mathrm{~K}$, natomiast najmniejsza $1,2 \mathrm{~K}$, przy średniej temperaturze ok. $150^{\circ} \mathrm{C}$. Średnia wartość błędu wyniosła 3,5K.

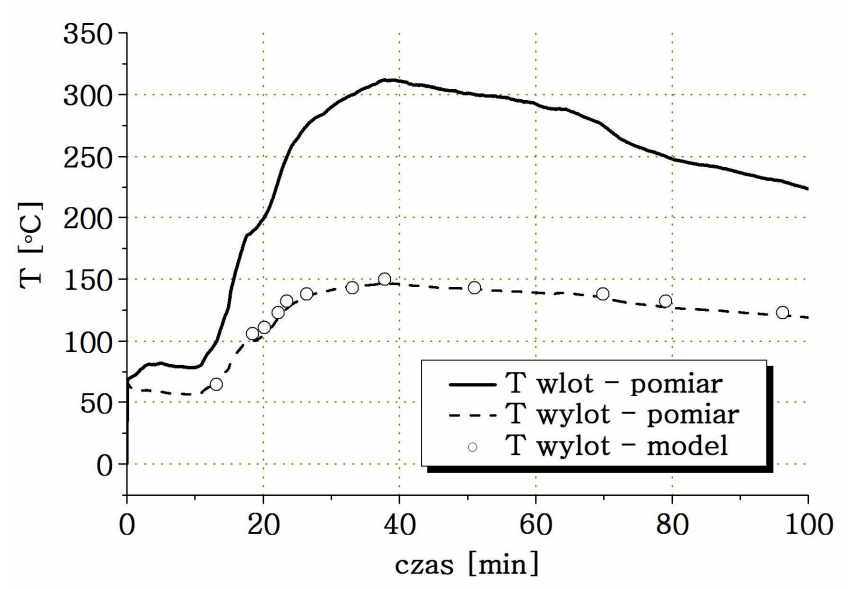

Rys. 7. Porównanie krzywej temperatury spalin na wylocie z wymiennika, wyznaczonej eksperymentalnie oraz stanowiącej rezultat obliczeń, przeprowadzonych na podstawie temperatury spalin na wlocie do wymiennika

Fig. 7. Comparison of outlet temperature curve, which was found as a result of experiment, with result of numerical simulation, calculated based on inlet temperature

\section{Podsumowanie}

Budowa modelu numerycznego, przeprowadzenie symulacji i pomyślnej walidacji uzyskanych danych umożliwia prowadzenie kompleksowych analiz pracy badanego akumulacyjnego wymiennika ciepła. Zamodelowanie układu z wykorzystaniem CFD pozwoliło na uzyskanie danych, stanowiących podstawę dla ustalenia nominalnego wsadu drewna dla danego paleniska oraz optymalnych wymiarów wymiennika ciepła, pozwalających na maksymalne wykorzystanie energii, generowanej w procesie spalania, a co za tym idzie maksymalizację sprawności wypadkowej układu. Aby w pełni określić warunki pracy urządzenia sugeruje się rozbudowę modelu o proces spalania, dzięki czemu zestaw wyników wzbogaci się o poziom emisji substancji szkodliwych.

Artykut opracowany $w$ ramach projektu badawczego Województwa Małopolskiego realizowanego przez firmę CEBUD we wspótpracy $z$ WEiP AGH. 


\title{
Literatura
}

[1] Kordylewski W.: Spalanie i Paliwa, Oficyna wydawnicza politechniki Wrocławskiej, Wrocław 2008.

[2] Kruczek K.: Kotły. Konstrukcje i obliczenia, Oficyna wydawnicza Politechniki Wrocławskiej, Wrocław 2001.

[3] Ogrzewanie drewnem, http://www.viessmann.pl/content/dam/internetpl/pdf_documents/ogrzewanie_drewnem [dostęp: 8 maja 2014 r.].

[4] Kotły na drewno, http://www.atmos.cz/poland/kotle-001-kotle-na-drevo [dostęp: 8 maja 2014 r.].

[5] Materiału informacyjne firmy CEBUD, http://www.cebud.eu/index.php?page=news\&kid=2\&pkid=29 [dostęp: 7 maja 2014].

[6] PN-EN 13229: wkłady kominkowe wraz z kominkami otwartymi na paliwa stałe. Wymagania i badania.

[7] Chaoqun L., Jiyuan T., Guan-Heng Y., Computational Fluid Dynamics. A practical Approach, Butterworth-Heinemann, Oxford 2013.

\section{THE NUMERICAL ANALYSIS OF OPERATION OF THE SMALL - SCALE BIOMASS HEATING DEVICES}

\begin{abstract}
S u m m a r y
Contemporary small-scale heating devices for applications in households have to be characterized by high efficiency of the energy conversion and operation parameters, which meet requirements related with the environment protection. Moreover, it is important to maintain relatively simple design, what provides reduction of the production costs. The numerical analysis is currently the most effective method for conduction of the optimization process, also in case of heating devices, such as biomass boilers or accumulative furnaces. The paper presents serie of possibilities to use numerical analysis tools for definition of the parameters of accumulative heat exchanger operation. Studied device is an integral element of system of small-scale biomass (mainly hardwood) furnace. In frames of experimental works, measurement of temperature and velocity of exhaust inside exchanger duct has been performed. The temperature distribution on the outer surface of accumulative mass has been found with use of infrared camera. Validation of numerical model was performed by measurement of temperature at the inlet and outlet of heat exchanger. Good agreement of experimental data and simulation has been reached. Results of numerical modeling, which are presented in the paper allowed to evaluate influence of exchanger geometry on degree of thermal energy accumulation and observation of temperature distribution on the surface of accumulative mass. Characteristic of the gas flux inside exhaust duct has been defined.
\end{abstract}

Keywords: Biomass furnaces, numerical modeling, CFD, wood

Przestano do redakcji: 9.12.2014 r.

Przyjęto do druku: 22.06.2015 r.

DOI:10.7862/rb.2015.77 